\title{
A utopia da palavra ou a demanda do idiolecto impossível: sobre Servidões, de Herberto Helder
}

\section{The utopia of the word or the demand of the impossible idiolect: on Servidões, by Herbert Helder}

\author{
Ricardo Gil Soeiro \\ Universidade de Lisboa, Lisboa, Portugal \\ ricardogsoeiro@hotmail.com
}

Resumo: O presente artigo visa apresentar uma leitura da obra Servidões (2013), da autoria do poeta português Herberto Helder. Analisa-se o contexto crítico da recepção de Servidões, sublinhando-se a dimensão final e testamentária da obra em apreço, embora se aponte igualmente para o propósito radical da poética herbertiana, a criação de uma língua dentro da língua.

Palavras-chave: Herberto Helder; língua dentro da língua; morte; poesia portuguesa contemporânea

Abstract: The present article wishes to present a reading of the work Servidões (2013), by the Portuguese poet Herberto Helder. An analysis of the critical context of the reception of Servidões is offered and the emphasis is placed upon the final and testamentary dimension of the work under review, whereas stressing, at the same time, the radical intent of the herbertian poetics, namely the creation of a language within a language. Keywords: Herberto Helder, Language within a language, Death, Portuguese contemporary poetry

Recebido em 10 de março de 2014.

Aprovado em 20 de abril de 2014. 
quem pode ainda recomeçar seja o que for?

$\mathrm{O}$ poema que se escreve - longo texto fluindo, denso e venenoso, a imitar a substância ao mesmo tempo vivificante e corruptora do sangue - não é sequer uma oferta dirigida a Deus. É a ironia, onde desliza a arma da nossa obscuridade. Tremenda força, essa. Escrevo o poema - linha após linha, em redor de um pesadelo do desejo, um movimento da treva, e o brilho sombrio da minha vida parece ganhar uma unidade onde tudo se confirma: o tempo e as coisas.

Herberto Helder

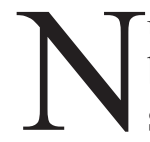

um tempo de aviltamento moral e de uniformização banalizadora, em que os meios de comunicação social servilmente se encontram sob o jugo de uma novilíngua empobrecedora, a publicação de um novo livro de poesia, como ocasião de liberdade da língua e do espírito, constitui um óbvio motivo de celebração e regozijo. Quando esse livro é da autoria de um poeta da envergadura de Herberto Helder, um tal motivo de júbilo é redobrado.

$\mathrm{Na}$ verdade, somente a dimensão maior de um poeta como Herberto Helder explica que Servidões (2013) se tenha tornado num acontecimento incontornável no panorama literário português, que, normalmente insípido, não conhece, de facto, grandes sobressaltos mediáticos. Não assim com Servidões. No suplemento "Ípsilon" (14 de junho de 2013), por exemplo, a ensaísta Rosa Maria Martelo destaca o livro como "um lance último", texto testamentário que se singularizaria pelo enfrentamento da finitude do sujeito poético que aí se encena, pela coragem inaudita de olhar a morte. Diz-nos a autora de $A$ forma informe (2010): "Há em Servidões um eu que ora fala a partir desse mundo, ora mede os 80 anos de idade e os limites físicos do corpo. Imaginase a morrer, concebe o corpo morto a atravessar as transmutações da matéria". ${ }^{1}$ E se António Guerreiro, no artigo "Herberto Helder, poeta da aura", se reporta a um efeito de reauratização, na senda das reflexões benjaminianas, já Diogo Vaz Pinto, citado por Luís Miguel Queirós, alude a essa força testamentária, afirmando que: "Não importa se escreverá ou não outros livros, este será sempre um livro final". ${ }^{2}$ Também no

\footnotetext{
${ }^{1}$ MARTELO, 2013, p. 9.

${ }^{2}$ PINTO apud QUEIRÓS, 2013, p. 11.
} 


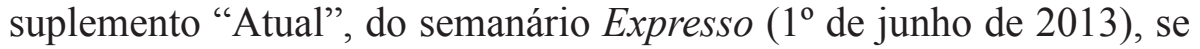
assiste a três aproximações a esta obra ímpar. Clara Ferreira Alves coloca a tónica, uma vez mais, no facto de este ser um livro final, terminal, "contendo uma salvação mais do que uma redenção de uma vida diferente das outras. E uma descoberta física: a mortalidade banal das humanas criaturas". ${ }^{3}$ José Mário Silva chama-lhe um livro crepuscular, ${ }^{4}$ ao passo que Pedro Mexia, no artigo "Luzes todas acesas", prefere salientar uma poesia "avessa à costura gramatical, esquiva à sintaxe comum". 5

Em todo o caso, independentemente do ângulo de análise que se decida privilegiar, certo é que a crítica se revelou unânime em relação à pujança imagética e ao conseguimento poético deste novo livro de Herberto Helder. De facto, perguntar-se-ia: em que é que se traduz um tal sucesso? Na verdade, o que Servidões vem trazer à actual paisagem literária portuguesa é, sem dúvida, uma poética profundamente amadurecida, quer na forma, quer nos seus conteúdos proposicionais. A despeito da unidade estrutural em torno da isotopia mortuária, observa-se uma riqueza prismática de temas e uma diversidade de registos discursivos que se aliam, de forma magistral, aos instrumentos prosódicos utilizados: destacamos, a título meramente ilustrativo, a mestria revelada ao nível do ritmo e da fluidez versificatória. Repare-se, ainda, no texto introdutório em prosa que enquadra os restantes textos poéticos e que condensa, in nuce, toda uma mundividência poética, sustentada por um eterno recomeçar da Palavra: "Mas penso que tudo isto é uma interminável preparação, uma aproximação. Porque o prestígio da poesia é menos ela não acabar nunca do que propriamente começar. É um início perene, nunca uma chegada seja ao que for". ${ }^{6} \mathrm{E}$ o modo perceptivo que resulta deste olhar perpetuamente inicial, o modo como o sujeito cognoscente se relaciona com o mundo, traduz-se numa espécie de oximórica aprendizagem da desaprendizagem:

[...] é preciso apanhar a ocasional distracção das coisas, e desaparecer; fugir para o outro lado, onde elas nem suspeitam da nossa consciência; e apanhá-las quando fecham as pálpebras, um momento, rápidas, e rapidamente

\footnotetext{
${ }^{3}$ ALVES, 2013, p. 7.

${ }^{4}$ SILVA, 2013, p. 9.

${ }^{5}$ MEXIA, 2013, p. 8.

${ }^{6}$ HELDER, 2013a, p. 12.
} 
pô-las sob o nosso senhorio, apanhar as coisas durante a sua fortuita distracção, um interregno, um instante oblíquo.?

O dístico inicial ("dos trabalhos do mundo corrompida/que servidões carrega a minha vida" ${ }^{\text {) }}$ aponta para uma indagação do eu, uma espécie de súmula existencial, em que o si-mesmo que se contempla ao espelho é o mesmo que examina o rosto desenhado pelas palavras. A componente visceralmente existencial e mesmo biográfica deixa-se, desde logo, entrever na anotação reiterada da idade do sujeito escrevente (80 anos), incluída, por exemplo, na datação da seguinte composição poética: "saio hoje ao mundo,/cordão de sangue à volta do pescoço,/e tão sôfrego e delicado e furioso,/de um lado ou de outro para sempre num sufôco,/iminente para sempre. 23.XI.2010: 80 anos". ${ }^{9}$ Ou ainda na referência explícita: "octagenário apenas, e a morte só de pensá-la calo". ${ }^{10}$ A consciência da própria mortalidade do sujeito é candente, marcando a sua presença na face visível e nas fissuras do texto, ora de forma explícita, ora de forma velada: "e eu sei quanto depressa morro". ${ }^{11}$

Servidões encena certamente o topos dos ultima verba, as últimas palavras com que se finaliza uma existência. Esse eu que heroicamente se interroga para, afinal, se descobrir mortal torna-se mero pretexto perecível nas mãos de deuses absortos. No magnífico livro Mortes imaginárias, Michel Schneider procura justamente compulsar as derradeiras palavras proferidas por célebres escritores e pensadores. Cada capítulo recria, com indesmentível erudição, os últimos momentos daqueles que, na iminência da sua própria extinção, encaram a proximidade tangível da morte. De Pascal a Kant, passando por Flaubert, Freud ou Nabokov (ao todo, são 36 autores), o tom oscila entre a amargura e a consolação, entre a beatitude e o desencanto. A seguinte passagem atesta as múltiplas irradiações simbólicas dos derradeiros instantes, apontando igualmente para a centralidade da problemática linguística para a auto-tanato-grafia que, em certa medida, o novo livro herbertiano é:

\footnotetext{
${ }^{7}$ HELDER, 2013a, p. 12.

${ }^{8}$ HELDER, 2013a, p. 19.

${ }^{9}$ HELDER, 2013a, p. 20.

${ }^{10}$ HELDER, 2013a, p. 109.

${ }^{11}$ HELDER, 2013a, p. 29.
} 
Última manifestação de um eu que em breve deixará de o ser, essas palavras chegam demasiado tarde, quando finalmente chegou a hora a respeito da qual nos interrogámos se seria então de dia ou não, se estaria frio ou não. Por vezes, fazemos então de tolo, de néscio que se tira da lama para se meter no atoleiro. Como por vezes nos matamos para não mais sermos obrigados a morrer, falamos para podermos calar-nos. Senhas, palavras de passe, palavras de passagem. Como as que lançamos à Esfinge. Não obstante, crente ou descrente, justo ou falso, doentio ou anedótico, altivo ou queixoso, de cada um, e seja como for, a última palavra será devorada pelo monstro justamente com o corpo que a exala. Não sei se no princípio era o verbo; temo bem que, no final, o verbo deixe de ser, para sobrar apenas um corpo desabitado pela palavra. ${ }^{12}$

Como texto maior acerca do fim, o que Servidões vem, afinal, fazer é iluminar, de novo, a absoluta necessidade de nos confrontarmos com a íntima possibilidade da nossa própria morte. Importaria, sem dúvida, auscultar o inigualável contributo de um filósofo como Martin Heidegger para a tematização do ser-para-a-morte (Sein-zum-Tode) que todo o ser-aí (Da-sein) genuinamente é (e os hifens como que comparecem para marcar graficamente a inextricabilidade entre esses elementos constitutivos: ser e morte, aí e ser). De acordo com a leitura heideggeriana, aceitar a finitude do projecto existencial (que todo o ser-aí é) significa, muito simplesmente, estar à altura da responsabilidade de uma existência autêntica (aqui escutam-se os ecos da influência kierkegaardiana sobre o pensador da Floresta Negra). A outra possibilidade seria o abandono a uma vida inautêntica, alheada da angústia (Angst) e mergulhada no quotidiano nivelador do das man. É na nota de rodapé n. 140 do $\S 51$ da obra monumental Sein und Zeit (1927) que Heidegger, no âmbito da sua analítica existenciária, se reporta à narrativa A morte de Ivan Ilitch (1886), de Lev Tolstoi, argumentando que esta obra do romancista russo retrata o fenómeno do abalo e do colapso desse "a gente morre" (man stirbt).

Uma tal interpelação ontológica remete-nos inevitavelmente para Rilke e para a distinção que o poeta alemão opera entre morte própria (der eigene Tod) e a morte alheia (der fremde Tod), sendo que aquela corresponde justamente à morte que nos diz respeito e que nos

${ }^{12}$ SCHNEIDER, 2011, p. 28-29. 
é insubstituível (em Die Aufzeichnungen des Malte Laurids Brigge, de 1910, Rilke instaura uma outra díade: a morte pequena - der kleine Tod - e a morte grande - der grosse Tod). Como humanos, demasiado humanos, somos - na óptica rilkiana - Todgebärer, aqueles que em si mesmos albergam a morte, revelando-se esta como realidade funda que existe, desde sempre, em embrião no nosso ventre. ${ }^{13}$

Efectivamente, a morte esteve presente, ab initio, na poesia herbertiana. No presciente ensaio "Em que língua escreve Herberto Helder?" (2009), Rosa Maria Martelo argumenta que:

A morte sempre teve parte na poesia de Herberto Helder. A morte e os mortos. A própria maneira como o poeta desde sempre implicou na escrita uma intensificação da subjectividade ao mesmo tempo solvente e expansiva, até no plano da condição da autoria, é em si mesma feita de encontros com a morte. ${ }^{14}$

Também aqui, no próprio coração negro de Servidões, Tanatos comparece, ocupando um lugar estrutural na escrita de Herberto Helder, mas, como na sua restante obra, a contrapresença antitética de Eros também se faz sentir com indisfarçável acutilância. À semelhança de volumes anteriores, aqui o desejo debate-se com a falta, o júbilo do conatus digladia-se com a dimensão trágica do existir. Em suma, com a poesia herbertiana estamos sempre perante a complexidade da vida ou, em termos ricœurianos, a alegria do sim na tristeza do finito.

Todavia, pese embora a iniludível dimensão tanatológica, estamos em crer que a dimensão futurante desta obra como que nos obriga a reposicionar o selo testamentário e final que, indubitavelmente, lhe podemos outorgar. Manuel de Freitas revela-se particularmente persuasivo quando, em "Baixa biografia", se reporta ao itinerário mais recente da obra poética herbertiana, mostrando como Servidões vem aprofundar a viragem inovadora que $A$ faca não corta o fogo (2009) verdadeiramente significou. Freitas defende que Helder tinha chegado em

${ }^{13}$ Cf. Rainer Maria Rilke, Das Buch von der Armut und vom Tode (1903), terceiro livro do ciclo poético Stunden-Buch (1905). O primeiro livro do ciclo em apreço intitula-se Das Buch vom mönchischen Leben (1899), e o segundo, Das Buch von der Pilgerschaft (1901). A edição por nós utilizada é a seguinte: RILKE, Rainer Maria. Gesammelte Gedichte. Frankfurt am Main: Insel-Verlag, 1962. p. 103.

${ }^{14}$ MARTELO, 2009, p. 153. 
Do mundo (1994) a um tal estado de arrebatamento alquímico, a um grau de intensidade imagética tão elevado, que uma tal assombrosa alquimia verbal - a vertigem promovida por uma tal gramática extrema - o teria conduzido a um beco sem saída: "Não era possível levar mais longe tão perfeita e compacta 'massa de beleza' em que as 'estrelas sísmicas' adquiriam um brilho cegante e radioactivo".${ }^{15} \mathrm{O}$ excesso de beleza teria encontrado um ponto de viragem que lhe teria permitido respirar de novo poeticamente. Esse "canto inteiro" (expressão que encontramos em Do mundo) teria, assim, dado lugar àquilo a que o crítico apelida de "irrupção disfórica" ${ }^{16}$ isto é, a um certo tom crepuscular que pontua de desencanto o júbilo incontido de uma outrora escrita transbordante. É neste sentido que Manuel de Freitas falará de recomeço e classificará este "inusitado renascimento lírico" ${ }^{17}$ da forma esclarecedora que se segue: "Apetece, pois, concluir que o 'canto inteiro' foi brutalmente substituído por uma 'fala cantante', mais rente à linguagem dita comum e ao mundo, num sentido histórico e já não exultantemente atemporal". ${ }^{18}$

Seja como for, a interrogação sobre a palavra e sobre o ofício poético persiste. Nesse gesto reflexivo, o poema é caracterizado como sendo "trémulo" e "fremente", apontando, pois, para a dimensão dinâmica e vibrátil da poiesis herbertiana. Todavia, mais do que isto, o que Servidões parece vir a aprofundar é a aspiração do sujeito poético a uma fala mais económica, mais abreviada, o que se observa no seguinte exemplo: "contudo quando acordei a minha mão estava em brasa,/contudo escrevi o poema cada vez mais curto para chegar/mais depressa", ${ }^{19} \mathrm{ou}$, num outro poema, "num poema rápido tão rápido que não doa" ${ }^{20}$ Não surpreende, com efeito, a utilização abundante da exclamação ("ah! um poema feito sobretudo de fogo forte e silêncio"21) ou da interjeição ("oh será que um poema entre todos pode ser absoluto?/: escrevê-lo, e ele ser a nossa morte na perfeição de poucas/linhas" ${ }^{22}$ ), na medida em que tais traços expressivos denotam o anelo do sujeito em apreender "um só nome

${ }^{15}$ FREITAS, 2013, p. 35-36.

${ }^{16}$ FREITAS, 2013, p. 36.

${ }^{17}$ FREITAS, 2013, p. 41.

${ }^{18}$ FREITAS, 2013, p. 36.

${ }^{19}$ HELDER, 2013a, p. 49.

${ }^{20}$ HELDER, 2013a, p. 56.

${ }^{21}$ HELDER, 2013a, p. 57.

${ }^{22}$ HELDER, 2013a, p. 58. 
para a terra toda", ${ }^{23}$ a busca da palavra absoluta que também encontramos, com outros matizes, por exemplo, em Lispector ou em Borges.

$\mathrm{Na}$ senda das reflexões deleuzianas em torno da literatura como gaguez criadora e da literatura menor, poder-se-ia afirmar que a poesia de Herberto Helder constitui um exercício de resistência que convida a língua a descarrilar. A experiência de despertencer alia-se a um idioma, a uma língua dentro da própria língua, como lemos em $A$ faca não corta $o$ fogo, ${ }^{24}$ poesia como sangue escrito. Ensaiando um "poema perfeito prometido que não nunca", ${ }^{25}$ o poeta exprime o seu desejo impossível: "quero criar uma língua tão restrita que só eu saiba,/e falar nela de tudo o que não faz sentido/nem se pode traduzir no pânico de outras línguas". ${ }^{26}$ Utopia poética seria, assim, delirar, lavrar fora do sulco, escapando ao uso maior com que, por toda a parte, nos cerca o quotidiano entorpecido. Já em “(guião)", incluído em Photomaton \& vox (1995), Herberto Helder nos fala da "destruição de uma sintaxe estrita" ${ }^{27}$ Também no segmento sintomaticamente intitulado "(movimentação errática)", lemos a vertente destruidora-criadora a que se pretende submeter a linguagem: "Levar a linguagem à carnificina, liquidar-lhe as referências à realidade, acabar com ela - e repor então o silêncio". ${ }^{28}$ Nesse gesto radical, na busca de um idiolecto singular que faça a língua tremer, sacudindo a canga que sempre oprime a estreiteza do linguajar representativo, a voz herbertiana cifra-se no apelo a uma fala híbrida e a uma mestiçagem discursiva que enriquecem esta poesia e que a tornam profundamente polifónica. A grande poesia tem esse condão: o de permitir vislumbrar intuições e parcelas de real que, de outro modo, resultariam desbotadas e insípidas. Edgar Allan Poe colocou a questão de forma magistral nos seguintes termos:

quando através da Poesia - ou pela Música - o mais arrebatador dos modos poéticos - nos encontramos desfeitos em lágrimas - choramos então - não [...] por um excesso de prazer, mas por uma certa dor, petulante, impaciente, face à nossa inabilidade de agarrar, agora, totalmente, aqui, na terra, de uma vez para sempre, essas

\footnotetext{
${ }^{23}$ HELDER, 2013a, p. 61.

${ }^{24}$ HELDER, 2009a, p. 572.

${ }^{25}$ HELDER, 2013a, p. 69.

${ }^{26}$ HELDER, 2013a, p. 57.

${ }^{27}$ HELDER, 2013b, p. 132.

${ }^{28}$ HELDER, 2013b, p. 126.
} 
alegrias divinas e extasiantes, das quais conseguimos alcançar através do poema, ou através da música, apenas breves e indeterminados vislumbres. ${ }^{29}$

Princípio de incêndio, fulgor no escuro, a poesia de Herberto Helder não cessa de nos apresentar esses frágeis e profundamente necessários vislumbres. Um jogo de espelhos, literalmente.

\section{Referências}

ALVES, Clara Ferreira. O poeta carnívoro. Expresso, $1^{\circ}$ jun. 2013. Atual, p. 6-9.

FREITAS, Manuel de. Baixa biografia. Cão Celeste, n. 4, p. 35-42, 2013.

GUERREIRO, António. Herberto Helder, poeta da aura. O Público, Lisboa, 14 jun. 2013. Ípsilon, p. 10.

HEIDEGGER, Martin. Sein und Zeit. Frankfurt am Main: Vittorio Klostermann, 1977. (Gesamtausgabe, v. 2).

HELDER, Herberto. Ofício cantante: poesia completa. Lisboa: Assírio \& Alvim, 2009a.

HELDER, Herberto. Os passos em volta. 10. ed. Lisboa: Assírio \& Alvim, 2009b.

HELDER, Herberto. Photomaton \& vox. 5. ed. Lisboa: Assírio \& Alvim, $2013 b$.

HELDER, Herberto. Servidões. Lisboa: Assírio \& Alvim, 2013a.

LOPES, Silvina Rodrigues. A inocência do devir: ensaio a partir da obra de Herberto Helder. Lisboa: Edições Vendaval, 2003.

MARTELO, Rosa Maria. Em que língua escreve Herberto Helder? Diacrítica, n. 23/3, p. 151-168, 2009.

MARTELO, Rosa Maria. Um lance último. O Público, Lisboa, 14 jun. 2013. Ípsilon, p. 9-10.

${ }^{29}$ POE, 2004, p. 153-154. 
MEXIA, Pedro. Luzes todas acesas. Expresso, $1^{\circ}$ jun. 2013. Atual, p. 8-9. PIMENTEL, Diana. Poema perfeito prometido que não nunca. Colóquio/ Letras, n. 185, p. 187-194, jan. 2014.

POE, Edgar Allan. Poética: textos teóricos. Lisboa: Fundação Calouste Gulbenkian, 2004.

QUEIRÓS, Luís Miguel. A arte de ser único. O Público, Lisboa, 14 jun. 2013. Ípsilon, p. 6-11.

SCHNEIDER, Michel. Mortes imaginárias. Lisboa: Cotovia, 2011.

SILVA, João Amadeu Oliveira Carvalho da. A poesia de Herberto Helder: do contexto ao texto: uma palavra sagrada na noite do mundo. Lisboa: Fundação Calouste Gulbenkian, 2004.

SILVA, José Mário. O terror da beleza. Expresso, $1^{\circ}$ jun. 2013. Atual, p. 9. TOLSTOI, Lev. A morte de Ivan Ilitch. Alfragide: Leya, 2009. 